\title{
Methods and Models Used to Parameterize the Infrared Absorption of Methane and Nitrous Oxide for Calculations Within the LLNL/UCLA Climate Model
}

\author{
K.E. Grant \\ A.S. Grossman \\ R.L. Tarp
}

November 1997

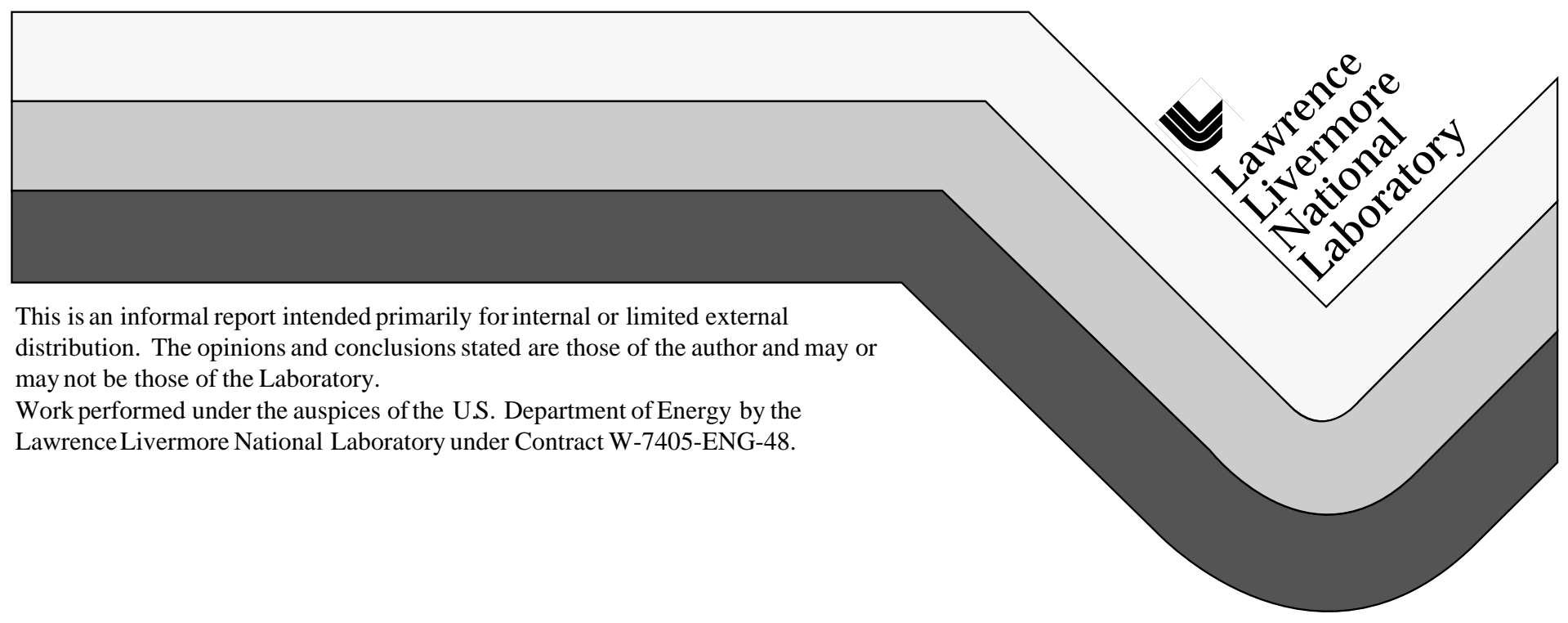




\section{DISCLAIMER}

This document was prepared as an account of work sponsored by an agency of the United States Government. Neither the United States Government nor the University of California nor any of their employees, makes any warranty, express or implied, or assumes any legal liability or responsibility for the accuracy, completeness, or usefulness of any information, apparatus, product, or process disclosed, or represents that its use would not infringe privately owned rights. Reference herein to any specific commercial product, process, or service by trade name, trademark, manufacturer, or otherwise, does not necessarily constitute or imply its endorsement, recommendation, or favoring by the United States Government or the University of California. The views and opinions of authors expressed herein do not necessarily state or reflect those of the United States Government or the University of California, and shall not be used for advertising or product endorsement purposes.

This report has been reproduced directly from the best available copy.

Available to DOE and DOE contractors from the Office of Scientific and Technical Information

P.O. Box 62, Oak Ridge, TN 37831

Prices available from (615) 576-8401, FTS 626-8401

Available to the public from the

National Technical Information Service

U.S. Department of Commerce 5285 Port Royal Rd.,

Springfield, VA 22161 


\title{
Methods and Models Used to Parameterize the Infrared Absorption of Methane and Nitrous Oxide for Calculations within the LLNL/UCLA Climate Model
}

\author{
Keith E. Grant, Allen S. Grossman, and Raymond L. Tarp \\ (keg@1lnl.gov) \\ Atmospheric Science Division, L-103 \\ Lawrence Livermore National Laboratory \\ Livermore, CA 94551
}

14 November 1997

\begin{abstract}
This report summarizes the tools and methods used to parameterize the radiative absorption by $\mathrm{CH}_{4}$ and $\mathrm{N}_{2} \mathrm{O}$ within the context of the infrared radiative transfer model of Chou and Suarez (1994), currently being used within the LLNL/UCLA climate model. We discuss in detail the physical formulation, computational implementation, and application of codes for line-by-line opacity calculations and generation of wide-band opacity probability distributions. In treating the wide-band opacity probability distributions, we derive the equations for weighting the opacity probabilities of individual wavenumber bins by the Planck function. Finally, we verify our implementation of $\mathrm{CH}_{4}$ and $\mathrm{N}_{2} \mathrm{O}$ absorption with the the Chou and Suarez model by comparision of radiative fluxes and tropospheric forcings with benchmark cases from ICRCCM and IPCC studies. Our parameterizations of the tropospheric forcing of ambient $\mathrm{CH}_{4}$ and $\mathrm{N}_{2} \mathrm{O}$ individually, in the absence of other trace gases, were within $13 \%$ of the ICRCCM medians. The combined forcing for the two gases was within $10 \%$ of the ICRCCM median. Our tropospheric radiative forcings for anthropogenic perturbation scenarios from IPCC and other sources compared within $2-11 \%$ with the benchmark values.
\end{abstract}

\section{INTRODUCTION}

Mitigation of anthropogenic global change requires developing an understanding of the scientific and economic issues involved in reducing greenhouse emissions. In the past, all greenhouse emissions have generally been treated as if they were emissions of a radiatively equivalent amount of carbon dioxide $\left(\mathrm{CO}_{2}\right)$. Radiative equivalence, in this sense, means that the same change in net radiative forcing at the tropopause is produced prior to any feedback responses. The research documented in this report is part of a project to investigate the extent to which methane $\left(\mathrm{CH}_{4}\right)$ and nitrous oxide $\left(\mathrm{N}_{2} \mathrm{O}\right)$ have forcing and climate response patterns distinguishable from those of radiatively equivalent $\mathrm{CO}_{2}$. The physical bases for such differences include differing spectral characteristics and spatial and seasonal distributions.

Specifically, this report summarizes the tools and methods used to parameterize the radiative absorption by $\mathrm{CH}_{4}$ and $\mathrm{N}_{2} \mathrm{O}$ within the context of the infrared radiative transfer model of Chou and Suarez (1994) currently being used within the LLNL/UCLA climate model. The Chou and Suarez model defines the bands and absorber contributions shown in Table 1 . In adding new absorbers to the model, we have stayed within the methodology and band structure of the original model. Thus, we have added absorption by $\mathrm{CH}_{4}$ and $\mathrm{N}_{2} \mathrm{O}$ as also shown in Table 1. Absorption by $\mathrm{CH}_{4}$ in band 5 and by $\mathrm{N}_{2} \mathrm{O}$ in band 7 were evaluated but not included. 
Together, they were found to contribute less than $0.005 \mathrm{~W} \mathrm{~m}^{-2}$ out of approximately $12 \mathrm{~W} \mathrm{~m}^{-2}$ to tropospheric forcing for ambient concentrations without other trace gases (see Table 3; Case 37G). In adding $\mathrm{CH}_{4}$ absorption to band 6, it was necessary to include a semi-empirical treatment of the correlation in the overlapping with $\mathrm{H}_{2} \mathrm{O}$. This is also considered below.

As discussed in Chou and Suarez (1994), depending on the band and the accuracy option chosen, one of two different methods may be used to compute the transmission between two pressure levels. In cases where accurate cooling rates in the middle atmosphere (pressures less than $10 \mathrm{hPa}$ ) are not required, computational efficiency is increased by use of a pressure scaled $k$-distribution algorithm. For applications in which greater accuracy is required, the slower use of pre-computed transmittance tables combined with two-parameter (p, T) scaling is done. Our implementation of $\mathrm{CH}_{4}$ and $\mathrm{N}_{2} \mathrm{O}$ absorption has used the latter approach. We discuss this in more detail below.

In brief, the development of the new absorption parameterizations for the bands and gases shown in Table 1 contained the following steps. First, line-by-line opacity calculations were done at 21 pressures between 0.01 and $1000 \mathrm{hPa}$ at temperatures of $170 \mathrm{~K}, 250 \mathrm{~K}$, and $330 \mathrm{~K}$. Depending on the pressure, gas, and band the spectral resolution for these calculations varied between $0.0005-0.01 \mathrm{~cm}^{-1}$. Next, the line-by-line opacities were binned into Planck-weighted opacity probability densities. The probability densities were then integrated and thinned to provide cumulative probability distributions of the opacities. These distributions were then used to calculate transmissions for 21 different absorber amounts for each combination of temperature and pressure. In calculating these transmissions, a 16 stream integration over propagation angle was done, assuming isotropic radiation intensities. Finally, a quadratic expansion for the temperature was done, reducing the transmissivities for each band and gas combination to a two-dimensional table depending on pressure and absorber amount for three temperature coefficients. We discuss the tools and concepts used to implement these steps in detail below. Tests done to validate the new parameterizations against published benchmark calculations are also presented.

Table 1: Spectral bands and absorbers in the Chou and Suarez infrared model

\begin{tabular}{|c|c|l|l|}
\hline \hline Band & Spectral Range $\left(\mathrm{cm}^{-1}\right)$ & Absorbers in the original model & New absorbers \\
\hline 1 & $0-340$ & $\mathrm{H}_{2} \mathrm{O}$ line & \\
\hline 2 & $340-540$ & $\mathrm{H}_{2} \mathrm{O}$ line & \\
\hline 3 & $540-800$ & $\mathrm{H}_{2} \mathrm{O}$ line, $\mathrm{H}_{2} \mathrm{O}$ continuum, $\mathrm{CO}_{2}$ & $\mathrm{~N}_{2} \mathrm{O}$ \\
\hline 4 & $800-980$ & $\mathrm{H}_{2} \mathrm{O}$ line, $\mathrm{H}_{2} \mathrm{O}$ continuum & \\
\hline 5 & $980-1100$ & $\mathrm{H}_{2} \mathrm{O}$ line, $\mathrm{H}_{2} \mathrm{O}$ continuum, $\mathrm{O}_{3}$ & \\
\hline 6 & $1100-1380$ & $\mathrm{H}_{2} \mathrm{O}$ line, $\mathrm{H}_{2} \mathrm{O}$ continuum & $\mathrm{CH}_{4}, \mathrm{~N}_{2} \mathrm{O}$ \\
\hline 7 & $1380-1900$ & $\mathrm{H}_{2} \mathrm{O}$ line & $\mathrm{CH}_{4}$ \\
\hline 8 & $1900-3000$ & $\mathrm{H}_{2} \mathrm{O}$ line & \\
\hline \hline
\end{tabular}

\section{CORKI - A Correlated- $\underline{k}$ Implementation}

CORKI is both a specific model and an underlying conceptual framework for a set of modules that in unison create a significant infrared atmospheric radiative transfer capability. The intent of the CORKI framework has been to create a set of radiative tools to progress from line-by-line spectral properties to either detailed stand-alone radiative transfer calculations or radiative parameterizations to be included in climate and 
chemistry models. CORKI is a replacement for an earlier set of models used in our previous studies such as Grossman and Grant (1994a). The development of CORKI was motivated by the need for a set of radiative transfer tools that met needs for efficiency, maintainability, and platform independence. Basic elements of the CORKI structure (Figure 1) include:

- HITRAN-96: a state of the art library of the spectrascopic properties of radiatively important atmospheric molecules. With the 1996 release, HITRAN includes HAWKS (HITRAN Advanced Work-Station). HAWKS facilitates selection and previewing of specific lines from within the entire database.

- KGEN: a moderately parallelized model for calculation of line-by-line opacities

- WC: an opacity post-processor to add the relatively smoothly varying water vapor continuum to line-by-line opacities from KGEN. The continuum opacities depends on layer temperature, pressure, and water vapor mixing ratio, as well as the wavelength. Because the Chou and Suarez infrared model already contained a treatment of continuum absorption, WC was not used in the current application.

- ABSORT: a program to calculate Planck weighted k-distributions from opacities generated by KGEN, and WC.

- TRANSMISS: a program to calculate tables of transmissivities for specific absorber amounts, pressures, and temperatures using k-distributions generated by ABSORT. Such transmissivities are then usable within the less detailed infrared radiative transfer models typical of a climate or atmospheric chemistry model.

- CORKI: a model to do accurate radiative transfer calculations for a vertically inhomogeneous atmosphere, directly using the correlated k-distribution technique. The term correlation in this application refers to the assumption that the mapping between wavenumber bins and opacity bins is approximately independent of altitude. If the opacity was factorable into a wavelength dependent absorption

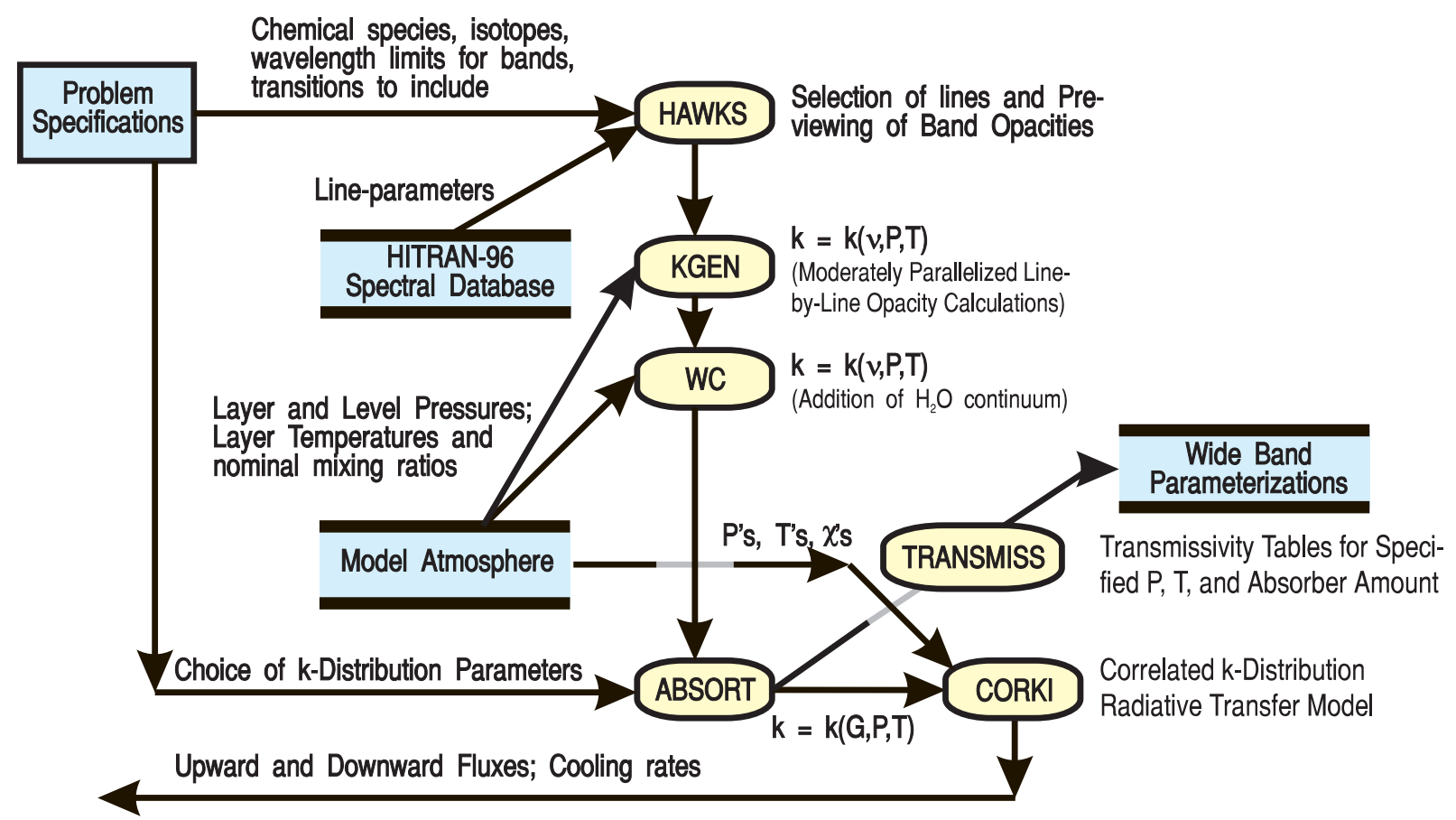

Figure 1: Structural overview of the Correlated- $k$ Implementation (CORKI) code suite for radiative transfer calculations and parameterizations. 
at a specified pressure and temperature and a function of pressure and temperature alone, then the correlation would be exact. In an actual vertically inhomogeneous atmosphere, the correlation assumption in an approximation. It works well in practice, partially because the radiation field in any layer depends strongly on near-neighbor layers with which the vertical correlation is high. This radiative transfer approach was not used for the current project, and will not be further pursued in this report. We have previously discussed it in Grant et al. (1992) and Grossman and Grant (1994a).

\section{KGEN}

\subsection{Introduction}

KGEN is a moderately parallelized opacity model developed to provide a core capacity for line-by-line atmospheric radiative transfer calculations at LLNL. As opposed to most existing line-by-line codes, KGEN has been designed specifically to run on symmetric multi-processors or workstation clusters.

Calculation of line-by-line opacities from spectroscopic data is the basic foundation of all atmospheric radiative transfer problems that include gaseous absorption and emission. The applications of such opacity calculations include: development of efficient radiative parameterizations for modeling the climatic and chemical effects of potential changes in trace gases, aerosols, and cloudiness, remote sensing, and visibility calculations. Remote sensing applications include both scientific and national security aspects pertaining to the effects of atmospheric constituents on specific sensor wavelengths.

By their very nature, line-by-line opacity calculations are computationally intensive. At atmospheric pressures below about $10 \mathrm{hPa}$, integration over spectral line-shapes requires a full Voigt treatment. Simultaneously, the half-width of the line becomes significantly narrower than at larger pressures. For the 50 wavenumber interval over which the far wings of a line are assumed to have influence, there may be over 250,000 spectral bins. More over, each bin may include a quadrature of the Voigt function (Lether and Wenston, 1990), resulting in over a million Voigt function evaluations per spectral line. The magnitude of this problem is multiplied by the number of lines in a desired band, often 2,000 to 12,000. Additionally, a library of spectral calculations for a particular wavenumber band and gas may require calculations at 3 separate temperatures and 26 separate pressure levels. These computational requirements have here-to-fore limited such codes to vector supercomputers.

We have used the KGEN opacity model to generate correlated-k (opacity probability) distributions for computationally efficient solar and terrestrial infrared radiative transfer calculations. Such k-distributions can be used directly for detailed radiative transfer calculations or be used to tabulate wide-band spectral atmospheric transmission as a function of path absorber amount, effective path pressure, and effective path temperature. Such wide-band transmission data are the basis for efficient interactive radiative transfer calculations within climate models. We calculated a library set of opacities for $\mathrm{CH}_{4}$ and $\mathrm{N}_{2} \mathrm{O}$ executing KGEN on a cluster of DEC Alpha workstations.

\subsection{Description of Computational Methods}

The absorption coefficient of a molecule at a particular wavenumber $v\left(\mathrm{~cm}^{-1}\right)$ and temperature is given by the product of the temperature dependent line strength $S(T)$ and the line shape factor $f\left(v-v_{0}\right)$, where $v_{0}$ is the position of the line center. Including the normalization of the line, we have

$$
\begin{gathered}
k_{v}=S(T) f\left(v-v_{0}\right), \\
S=\int_{-\infty}^{\infty} k_{v} d v .
\end{gathered}
$$


The variation of the line strength, $\mathrm{S}$, with temperature is given by

$$
S(T)=S\left(T_{r}\right) \frac{Q\left(T_{r}\right)}{Q(T)} \frac{1-e^{-h c v_{0} / K T}}{1-e^{-h c v_{0} / K T_{r}}} \exp \left[-\frac{h c E_{i}}{K}\left(\frac{1}{T}-\frac{1}{T_{r}}\right)\right],
$$

where $T_{r}$ is a reference temperature, $E_{i}$ is the energy of the lower state of transition, and $Q(T)$ is the internal partition function for the molecule in question (Liou, 1992). The evaluation of Eqn. 2 is facilitated by $S\left(T_{r}\right)$ and $E_{i}$ being part of the spectral data provided for each line in the HITRAN database. A function for the evaluation of $\mathrm{Q}\left(T_{r}\right) / Q(T)$ based on quadratic fits has also been included in the HITRAN release (Gamache et al., 1990).

The line shape factor is given by

$$
f_{v}\left(v-v_{0}\right)=\frac{1}{\alpha_{D} \sqrt{\pi}} K(x, y)
$$

where $\alpha_{D}$ is the Doppler width (Liou, 1992). Further defining $\alpha$ to be the Lorentz half-width; $y=\alpha / \alpha_{D}$, and $x=\left(v-v_{0}\right) / \alpha_{D}$, the Voigt function is defined by

$$
K(x, y)=\frac{y}{\pi} \int_{-\infty}^{\infty} \frac{1}{y^{2}+(x-t)^{2}} e^{-t^{2}} d t .
$$

In the lower atmosphere where the Lorentz half-width is much greater than the Doppler width, the line shape simplifies to the Lorentz profile. In the upper atmosphere, where the Lorentz width is negligible, the line shape simplifies to the Doppler profile. In between these extremes, the more complex Voigt profile must be used.

We perform the many Voigt function evaluations required using the method of Lether and Wenston (1990). This method is based on a corrected trapezoidal integration in which the number of terms can be varied to trade-off computational speed and accuracy. Lynas-Gray (1993) had subsequently implemented this algorithm for vector processors. Continued KGEN development efforts will include additional optimization of our application of this algorithm as well as further development of post-processing, testing, and analysis tools. Output from the KGEN model is to NetCDF files, facilitating platform portability of the data, self-documentation, and ease of further analysis.

The KGEN model has been parallelized and tested on a DECAlpha cluster using the Message Passing Interface (MPI) described by Gropp et al. (1994). The accuracy of the code was verified against a previous model (Grossman and Grant, 1994). The trapezoidal scheduling algorithm of Tzen and Ni (1993) was implemented to load balance the calculation of opacities in the different spectral bins affected by each spectral line. We have verified linear increases in through-put for one to five slave processors on ten CPU (central processing unit) machines. For a larger number of processors, competition with other tasks resulting in thrashing delays, resulting in a noticeable decrease in computational efficiency. Avoidance of such tasking conflicts requires gang scheduling of CPUs.

\section{ABSORT}

\subsection{Background}

In a paper by Lacis and Oinas (1991), a method was described for treating transmission calculations in infrared radiative transfer problems for a vertically inhomogeneous atmosphere in which there is non-gray gaseous absorption. The technique, known as the correlated $k$-distribution method, utilizes a mapping of the 
opacity-frequency relation into an opacity-probability relation within a particular frequency interval. We have previously summarized the basic theory and some results of applying the method in Grossman and Grant (1994a). The cumulative probability distribution, used in defining the "c-k" method is given by

$$
G(k)=\int_{-\infty}^{k} f\left(k^{\prime}\right) d \log k^{\prime},
$$

where $f\left(k^{\prime}\right) d \log k^{\prime}$ is the fraction of the fraction of the frequency interval occupied by absorption coefficients between $\log k^{\prime}$ and $\log k^{\prime}+d \log k^{\prime}$, i.e. the probability density function. Using these definitions, the transmission through a single, homogeneous layer can be expressed in three equivalent forms:

$$
\begin{aligned}
T(u) & =(\Delta v)^{-1} \int_{\Delta v} e^{-k(v) u} d v, \\
& =\int_{-\infty}^{\infty} f(k) e^{-k u} d \log k, \\
& =\int_{0}^{1} e^{-k(G) u} d G,
\end{aligned}
$$

where $u$ is the path absorber amount. The advantage of making these transformations is in going from an integral in which $k$ is rapidly varying over orders of magnitude to one in which $k$ is monotonically and smoothly increasing. The properties of smoothness and monotonicity yield themselves to efficient numerical evaluation of the integral. The term "correlated" refers to the assumption that, for a vertically inhomogeneous atmosphere, the mapping or ordering relating wavelength bins to opacity bins will remain constant. For any real atmosphere this is an approximation. It holds exactly under the assumption the wavelength variation and pressure-temperature variation of the opacities can be separated into independent factors.

Now consider an infrared band of sufficient width that not only the variation in the opacity but also the variation in the Planck function must be considered. We can sub-divide such a band, as has been done by Chou and Suareez (1994), so that within each sub-band the Planck function could be taken as constant. We can then write the Planck-weighted total band transmission as the sum over the sub-bands given by

$$
T(u)=\sum_{j=1}^{J} \frac{B_{j}(T)}{B(T)} \Delta v_{j} \int_{0}^{\infty} e^{-k u} f_{j}(k) d \log (k),
$$

where $B(T)=\sum_{j} B_{j}(T) \Delta v_{j}$ is the band-integrated Planck flux, $B_{j}(T)$ is the Planck flux in the $j t h$ sub-band, and $f_{j}(k)$ is the probability density function of the absorption coefficient in the $j$ th sub-band. Discretizing the integral over $k$ in Eqn. 7 into a sum over $\mathrm{N}$ terms and rearranging, we obtain

$$
\begin{aligned}
T(u) & =\sum_{n=1}^{N} e^{-k_{n} u}\left[\Delta \log \left(k_{n}\right) \sum_{j=1}^{J} \frac{B_{j}(T)}{B(T)} \Delta v_{j} f_{j}\left(k_{n}\right)\right], \\
& =\sum_{n=1}^{N} e^{-k_{n} u} \Delta \tilde{G}_{n},
\end{aligned}
$$

with $\Delta \tilde{G}_{n}$ interpreted as being a Planck-weighted probability increment or density. If we now go to the limiting case of the sub-bands being single wavelength bins, the unweighted probability density terms $f_{j}\left(k_{n}\right)$ become delta functions, since the opacity for a particular wavelength bin will lie in one and only one opacity bin. In this case, we can express $\Delta \tilde{G}_{n}$ by

$$
\Delta \tilde{G}_{n}=\left[\Delta \log \left(k_{n}\right) \sum_{j=1}^{J} \frac{B_{j}(T)}{B(T)} \Delta v_{j} \delta\left(k_{j}-k_{n}\right)\right] G_{\infty}^{-1},
$$


saving the necessity of an intermediate step of calculating separate $k$-distributions for each sub-band in transforming from line-by-line opacities to a total band $k$-distribution. The normalization factor, $G_{\infty}^{-1}$, is defined such that $\sum_{n} \Delta \tilde{G}_{n}=1$. Examples of the resulting opacity Planck-weighted probability density function and cumulative probability distribution are show in Figures 2 and 3.

The practical effect of adding the Planck weighting is to give unequal weighting to the different wavelength bins in calculating the probability density function. Specifically, as discussed by Chou and Suarez (1994) and Liou (1992), the terms defining the interaction of the radiation field with a discrete atmospheric layer are differences of individual terms of the form

$$
Q=\sum_{j=1}^{J} B_{j}(T) \Delta v_{j} e^{-k_{j} u},
$$

where the sum is taken over the individual wavenumber bins. In this form, it is readily apparent that the weight given to each exponential transmission involving $k_{j}$ is given by $B_{j}(T) \Delta v_{j}$. By mapping the weights of individual wavenumber bins into the $N$ discrete opacity bins $\Delta \log \left(k_{n}\right), n=1,2,3, \ldots, N$, and subsequently renormalizing, we arrive again at the result of Eqn. 9.

Rather than assuming $B_{v}(T)$ to be constant over some sub-band or evaluating it in full for each of many wavelength bins, we can evaluate it at some subset of wavelengths and interpolate in-between. In practice, the variation in the shape of the Planck function over the range of atmospheric temperatures is of far less importance than its original inclusion. Chou and Suarez (1994) have noted that, for the weighting purposes described above, the evaluation of the Planck weighting at a temperature of $250 \mathrm{~K}$ is accurate for all atmospheric use.

\subsection{Implementation Issues}

At low pressures, the centers of strong absorption lines are not appreciably broadened from their doppler limits. The effect of this on the opacity probability distributions is to create a small but optically significant probability for opacities relatively large compared to the remainder of the distribution. This results in a sharp peak in the opacities for cumulative probabilities between 0.99 and 1 . In choosing the values of cumulative probability, $\mathrm{G}$, for the find $k$-distribution $k(\mathrm{G})$, accuracy requires care in resolving this peak.

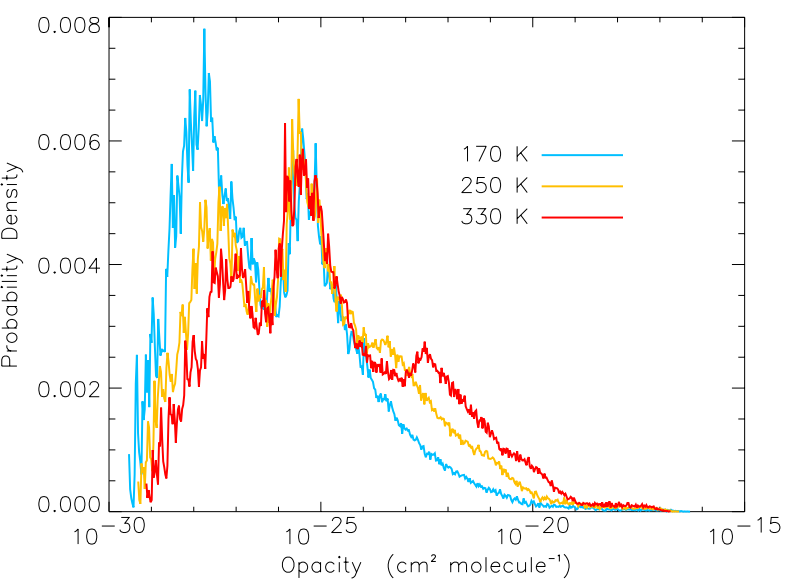

Figure 2: Planck-weighted probability density functions for $\mathrm{CH}_{4}$ opacities in band 6 at a pressure of $0.01 \mathrm{hPa}$ and at temperatures of $170 \mathrm{~K}, 250 \mathrm{~K}$, and $330 \mathrm{~K}$.

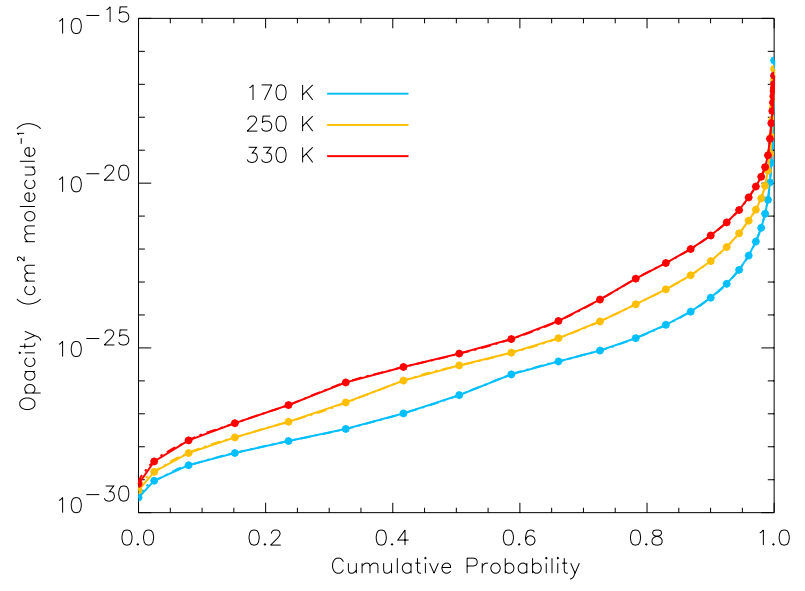

Figure 3: Planck-weighted cumulative probability distributions for $\mathrm{CH}_{4}$ opacities in band 6 at a pressure of $0.01 \mathrm{hPa}$ and at temperatures of $170 \mathrm{~K}, 250 \mathrm{~K}$, and $330 \mathrm{~K}$. 
Table 2: The first values, intervals, and sizes of the pre-computed tables of the regression coefficients $a, b$, and $c$ of Eqn. 13 for transmittance calculations. The units of $\mathrm{u}$ for both $\mathrm{CH}_{4}$ and $\mathrm{N}_{2} \mathrm{O}$ are $\mathrm{g} \mathrm{cm}^{-2}$. The units of pressure are $\mathrm{hPa}$.

\begin{tabular}{|c|c|c|c|c|c|c|}
\hline \hline Absorber & $\log _{10}(\mathrm{u})_{1}$ & $\Delta \log _{10}(\mathrm{u})$ & $\mathrm{u}$ table size & $\log _{10}\left(\mathrm{p}_{\mathrm{e}}\right)_{1}$ & $\Delta \log _{10}\left(\mathrm{p}_{\mathrm{e}}\right)$ & $\mathrm{p}_{\mathrm{e}}$ table size \\
\hline $\mathrm{CH}_{4}$ & -8.0 & 0.3 & 21 & -2 & 0.2 & 26 \\
\hline $\mathrm{N}_{2} \mathrm{O}$ & -8.0 & 0.3 & 21 & -2 & 0.2 & 26 \\
\hline \hline
\end{tabular}

In creating the probability distribution $f(k)$ from $k(v)$, we may start with mapping several hundred thousand wavelength bins into several thousand $k$-distribution bins. The $k$-distribution bins are most often chosen to have equal increments in $\log (k)$. In order to use the $\mathrm{c}-\mathrm{k}$ method for atmospheric modeling, we must establish the necessary resolution in $\mathrm{G}$ at the top of the atmosphere where the resolution requirements are most stringent. The same set of G's must then be used for all vertical layers below. To facilitate this, we fit the relation

$$
G(\hat{k})=1+e^{-a \hat{k}^{b}}-\hat{k} e^{-a},
$$

for the coefficients $a$ and $b$ with equally spaced $\hat{k}$ defined by

$$
\hat{k}=\frac{\log (k)-\log \left(k_{\min }\right)}{\log \left(k_{\max }\right)-\log \left(k_{\min }\right)} .
$$

Given the number of $\mathrm{G}$ points desired and the coefficients $a$ and $b$, the cumulative probability discretization is uniquely determined. This provides a compact method of specifying a particular G discretization to ABSORT for analyses in which the output gridding has already been determined from a prior analysis. Having calculated the cumulative probability distribution for a layer at specified points in $\log (k)$, the inversion to $\log (k(G))$ at specified $\mathrm{G}$ points is accomplished via piecewise cubic Hermite interpolation.

\section{TRANSMISS}

TRANSMISS accomplishes the final step in going from spectroscopic data tables to tables of transmission for specified absorber path amounts, pressures, and temperatures. To implement absorption by $\mathrm{CH}_{4}$ and $\mathrm{N}_{2} \mathrm{O}$ within the model of Chou and Suarez (1994), path transmittances for each gas within each affected wavelength band were calculated at 26 pressures, 21 absorber amounts, and 3 temperatures. Calculations were done at temperatures of $170 \mathrm{~K}, 250 \mathrm{~K}$, and $330 \mathrm{~K}$ Because the temperature dependence of the transmittances is smooth and relatively slowly varying, the table look-up can be reduced from threedimensional to two-dimension using a quadratic fit in temperature. We then have,

$$
\mathrm{T}\left(u, p_{e}, T_{e}\right)=a\left(u, p_{e}\right)+b\left(u, p_{e}\right)\left(T_{e}-250 K\right)+c\left(u, p_{e}\right)\left(T_{e}-250 K\right)^{2}
$$

where $u$ is the path absorber amount and $p_{e}$ and $T_{e}$ are absorber-weighted effective pressures and temperatures for a given path. Values of flux transmittances are tabulated for the pressures and absorber amounts given in Table 2. Because the tables of transmittances are precomputed, it was not necessary to use a single effective propagation angle, or equivalently a diffusivity factor to achieve computational efficiency. We therefore used a 16 stream angular integration assuming isotropic intensity in calculating the final flux transmissivities. 


\section{Using the Parameterization}

The transmissivity data for $\mathrm{CH}_{4}$ and $\mathrm{N}_{2} \mathrm{O}$ is implemented within the Chou and Suarez model as transmissivities at a temperature of $250 \mathrm{~K}$ and linear and quadratic temperature expansion coefficients. For each band and gas, the data are provided at the pressures and absorber amounts given in Table 2. Temperatures within the model are handled internally as deviations from $250 \mathrm{~K}$.

For each absorber in the model, the column integrated amount from the top of the atmosphere to each level (layer boundary) is calculated. The absorber-weighted integrals of pressure and temperature deviation are also calculated. When a transmissivity between two levels is needed, the absorber path-amount, and effective average pressure and temperature deviation are thus readily available. Given these three parameters, the model locates the bounding pressures and absorber amounts in the transmissivity table, and interpolates the transmissivity coefficients to the current pressure and absorber. The quadratic expansion is then made to evaluate the needed transmissivity.

The overlapping between successive absorbers is handled via the transmission product rule. If we denote the mean flux transmission of the $j$ 'th gas over a band as $T_{j}$ and the deviation from the mean as $T_{j}^{\prime}$, then we can write the overlapped transmission $\mathrm{T}_{12}$ of two gases as

$$
\mathrm{T}_{12}=\mathrm{T}_{1} \mathrm{~T}_{2}+\frac{\int_{\Delta v} B_{v} \mathrm{~T}_{1}^{\prime}(v) \mathrm{T}_{2}^{\prime}(v) d v}{\int_{\Delta v} B_{v} d v},
$$

where the first term on the right constitues the standard product rule and the second term is nonzero only if the variation of transmissivity of the two gases is spectrally correlated. In testing the parameterization of $\mathrm{CH}_{4}$ in band 6, we discovered that, while the absorption by $\mathrm{CH}_{4}$ alone or overlapped only with $\mathrm{N}_{2} \mathrm{O}$ seemed to be correct, the absorption overlapped with $\mathrm{H}_{2} \mathrm{O}$ was too large. For example, in a test of the forcing due to the 1990-1995 increase in $\mathrm{CH}_{4}$ with other gases held constant, we initially calculated a forcing of $0.71 \mathrm{~W} \mathrm{~m}^{-2}$ rather than the $0.52 \mathrm{~W} \mathrm{~m}^{-2}$ of our benchmark calculation. This discrepancy is explainable as the result of ignoring a positive correlation in Eqn. 14. In treating the overlap of $\mathrm{CO}_{2}$ and $\mathrm{H}_{2} \mathrm{O}$ in band 3, Chou and Suarez (1994) had solved the problem by dividing the band into three sub-bands. However, in making our modifications to the original model, we did not want to change the existing parameterization of $\mathrm{H}_{2} \mathrm{O}$ in band 6 . We solved this by using a semi-empirical parameterization for the overlap correlation having the correct limiting properties and having one parameter tuned to our ambient benchmark forcing studies. The overlap parameterization we used is given by

$$
\mathrm{T}_{12}=\mathrm{T}_{1} \mathrm{~T}_{2}\left[1+\gamma\left(1-\mathrm{T}_{1}\right)\left(1-\mathrm{T}_{2}\right) \frac{p}{p_{0}}\right],
$$

with $\gamma$ equal to 1.85 .

To validate our implementation of $\mathrm{CH}_{4}$ and $\mathrm{N}_{2} \mathrm{O}$ absorption, we have compared our results for a number of radiative flux and forcing calculations with those from other studies. In Table 3, we compare our results of flux calculations with those from the Intercomparison of Radiation Codes use in Climate Models (ICRCCM) presented by Ellingson et al. (1991). Comparisons are at the surface tropopause, and the top of the atmosphere. These results, being for $\mathrm{CH}_{4}$ and $\mathrm{N}_{2} \mathrm{O}$ only, are unaffected by the overlap correlation correction of Eqn. 15. They are thus a direct measure of the accuracy of the new parameterizations independent of other absorbing gases.

Comparing our results with ICRCCM results in Table 3, our parameterizations of the tropospheric forcing of ambient $\mathrm{CH}_{4}$ and $\mathrm{N}_{2} \mathrm{O}$ individually, in the absence of other trace gases, were within $13 \%$ of the ICRCCM medians. These forcing estimates are based on an upward surface flux of $423 \mathrm{~W} \mathrm{~m}^{-2}$ for the mid-latitude 
summer surface temperature of $294 \mathrm{~K}$. We would expect the medians results to be less influenced by outlyers than the means. The combined forcing for the two gases was within 10\% of the ICRCCM median.

In Table 4, we compare radiative forcing calculated at the tropopause for a clear-sky mid-latitude summer atmosphere and a global average atmosphere, including clouds. Radiative forcing cases were selected from several sources, including the International Panel on Climate Change Second Assessment Report (IPCC, 1995). In all test cases, the results of our parameterizations for $\mathrm{CH}_{4}$ and $\mathrm{N}_{2} \mathrm{O}$ absorption are within acceptable ranges of variability (2-11\%) as compared with other studies. While the band 6 transmission overlap of $\mathrm{CH}_{4}$ with $\mathrm{H}_{2} \mathrm{O}$ was corrected using Eqn. 15, the same correlation strength parameter was used for all calculations. The consistent agreement over all cases, without further tuning, is an indication that the use of Eqn. 15 is robust.

\section{Acknowledgements}

Computational resources for this research were partially provided by the Livermore Computing Center under ACISE (Advanced Computing Initiative for Science and Engineering) and the Multiprogrammatic and Institutional Computing (M\&IC) Initiative. Work was performed under the auspices of the U.S. Dept. of Energy by the Lawrence Livermore National Laboratory under contract No. W-7405-Eng-48.

Table 3: Comparison with ICRCCM infrared fluxes for $\mathrm{CH}_{4}$ and $\mathrm{N}_{2} \mathrm{O}$ cases

\begin{tabular}{|c|c|c|c|c|c|}
\hline \multirow{2}{*}{ ICRCCM Case } & \multirow{2}{*}{$\begin{array}{l}\text { New Param- } \\
\text { eterization } \\
\left(\mathrm{W} \mathrm{m}^{-2}\right)\end{array}$} & \multicolumn{4}{|c|}{ ICRCCM } \\
\hline & & $\begin{array}{l}\text { Median } \\
\left(\mathrm{W} \mathrm{m}^{-2}\right)\end{array}$ & $\begin{array}{l}\text { Range } \\
\left(\mathrm{W} \mathrm{m}^{-2}\right)\end{array}$ & $\begin{array}{c}\text { Mean } \\
\left(\mathrm{W} \mathrm{m}^{-2}\right)\end{array}$ & $\begin{array}{l}\text { Std. Dev. } \\
\left(\mathrm{W} \mathrm{m}^{-2}\right)\end{array}$ \\
\hline \multicolumn{6}{|c|}{$37 \mathrm{~A}(11)-1.75 \mathrm{ppmv} \mathrm{CH}_{4}$} \\
\hline Surface & 417.19 & 417.06 & 7.73 & 415.77 & 2.20 \\
\hline Tropopause & 419.37 & 418.76 & 3.86 & 418.23 & 1.13 \\
\hline TOA & 419.25 & 418.55 & 3.84 & 417.96 & 1.14 \\
\hline \multicolumn{6}{|c|}{$37 \mathrm{~B}(9)-0.28 \mathrm{ppmv}_{2} \mathrm{O}$} \\
\hline Surface & 417.13 & 417.22 & 8.24 & 415.70 & 2.69 \\
\hline Tropopause & 419.68 & 419.13 & 5.15 & 418.57 & 1.44 \\
\hline TOA & 419.33 & 418.58 & 5.38 & 418.06 & 1.58 \\
\hline \multicolumn{6}{|c|}{$37 \mathrm{G}(10)-\mathrm{CH}_{4} \& \mathrm{~N}_{2} \mathrm{O}$} \\
\hline Surface & 411.26 & 411.64 & 14.71 & 409.18 & 4.58 \\
\hline Tropopause & 415.71 & 414.91 & 11.05 & 413.63 & 3.11 \\
\hline TOA & 415.28 & 414.29 & 15.05 & 412.66 & 4.14 \\
\hline
\end{tabular}


Table 4: Comparison with MLS, global average, and IPCC forcing cases

\begin{tabular}{|c|c|c|c|}
\hline Case & $\begin{array}{c}\text { New Parameterization } \\
\qquad\left(\mathrm{W} \mathrm{m}^{-2}\right)\end{array}$ & $\begin{array}{l}\text { Comparison } 1 \\
\left(\mathrm{~W} \mathrm{~m}^{-2}\right)\end{array}$ & $\begin{array}{l}\text { Comparison } 2 \\
\quad\left(\mathrm{~W} \mathrm{~m}^{-2}\right)\end{array}$ \\
\hline $\begin{array}{l}\text { MLS - Clear Sky } \\
\text { No other gases present } \\
\mathrm{CH}_{4}: 1.72-3.44 \text { ppmv }\end{array}$ & 1.63 & $\begin{array}{c}\text { Grossman \& Grant } \\
(1994 b) \\
1.67\end{array}$ & \\
\hline $\begin{array}{l}\text { MLS - Clear Sky } \\
\text { Ambient trace gases } \\
\mathrm{CH}_{4}: 0-1.72 \text { ppmv }\end{array}$ & 1.81 & $\begin{array}{c}\text { Grossman \& Grant } \\
(1994 b) \\
1.69\end{array}$ & $\begin{array}{c}\text { Ramaswamy (1993) } \\
2.02\end{array}$ \\
\hline $\begin{array}{l}\text { MLS - Clear Sky } \\
\text { Ambient trace gases } \\
\mathrm{CH}_{4}: 1.72-3.44 \text { ppmv }\end{array}$ & 0.769 & $\begin{array}{c}\text { Grossman \& Grant } \\
(1994 b) \\
0.718\end{array}$ & $\begin{array}{c}\text { Shine (1993) } \\
0.852\end{array}$ \\
\hline $\begin{array}{l}\text { Global Average Atmos. } \\
1990 \text { Ambient Gases } \\
\text { CH4: } 1.65-3.30 \text { ppmv }\end{array}$ & 0.527 & $\begin{array}{c}\text { Grossman \& Grant } \\
(1994 b) \\
0.521\end{array}$ & $\begin{array}{l}\text { Ramanathan et al. } \\
\qquad \begin{array}{c}(1987) \\
0.550\end{array}\end{array}$ \\
\hline $\begin{array}{l}\text { IPCC } 1990-1995 \\
1990 \text { Ambient Gases } \\
\mathrm{N}_{2} \mathrm{O}: 0.310-0.314\end{array}$ & 0.015 & $\begin{array}{l}\text { IPCC } \\
0.016\end{array}$ & \\
\hline $\begin{array}{l}\text { IPCC } 1990-2000 \\
1990 \text { Ambient Gases } \\
\mathrm{N}_{2} \mathrm{O}: 0.310-0.319 \\
\end{array}$ & 0.032 & $\begin{array}{l}\text { IPCC } \\
0.033 \\
\end{array}$ & \\
\hline
\end{tabular}

\section{References}

Chou, Ming-Dah, and Max J. Suarez, 1994: An Efficient Thermal Infrared Radiation Parameterization for Use in General Circulation Models, Technical Report Series on Global Modeling and Data Assimilation, Vol 3, NASA Technical Memorandum 104606, Vol 3.

Ellingson, R.G., J. Ellis, and S. Fels, 1991: The Intercomparison of Radiation Codes Used in Climate Models: Long Wave Results, J. Geophys. Res., 96 (D5), 8929-8953.

Gamache, R.R., R.L. Hawkins, and L.S. Rothman, 1990: Total internal partition sums in the temperature range 70-3000 K: Atmospheric linear molecules," J. Mol. Spectrosc. 142, 205-219.

Gropp, William, Ewing Lusk, and Anthony Skjellum, 1994: Using MPI -- Portable Parallel Programming with the Message-Passing Interface, M.I.T. Press, Cambridge, MA.

Grant, K.E., A.S. Grossman, J.B. Pollack, and R. Freedman, 1992: A Correlated k-distribution Model of the Heating Rates for $\mathrm{CH}_{4}$ and $\mathrm{N}_{2} \mathrm{O}$ in the Atmosphere between 0 and $60 \mathrm{~km}$, Proceedings, 15th Annual Review Conference on Atmospheric Transmission Models, June 2-3, 1992, Bedford, MA. (also LLNL Report UCRL-JC-110364).

Grossman, A.S., and K.E. Grant, 1994a: A correlated k-distribution model of the heating rates for atmospheric mixtures of $\mathrm{H}_{2} \mathrm{O}, \mathrm{CO}_{2}, \mathrm{O}_{3}, \mathrm{CH}_{4}$ and $\mathrm{N}_{2} \mathrm{O}$ in the $0-2500 \mathrm{~cm}^{-1}$ wave number region at altitudes between 0 and $60 \mathrm{~km}$. Proceedings of The 8th Conference on Atmospheric Radiation, American Meteorological Society, Nashville, Tenn., Jan. 23 - 28, 97-99. 
Grossman, A.S., and K.E. Grant, 1994b: Tropospheric Radiative Forcing of $\mathrm{CH}_{4}$, LLNL Report UCRL-ID116533, Lawrence Livermore National Laboratory.

IPCC, 1995: Second Assessment Report on Climate Change, International Panel on Climate Change.

Lacis A., And V. Oinas, 1991: A description on the corelated $\mathrm{k}$ distribution for modeling nongray gaseous absorpiton, emission, and multiple scattering in vertically inhomogeneous atmospheres, J. Geophys. Res., 96, D5, 9027-9063.

Liou, K.N., 1992: Radiation and Cloud Processes in the Atmosphere, Oxford Monographs on Geology and Geophysics No. 20, Oxford University Press, New York.

Lether, F.G. \& Wenston, P.R., 1990: An Algorithm for the Numerical Computation of the Voigt Function, Applied Mathematics and Computation, 35, 277-289.

Lynas-Gray, A.E., 1993: A Fast Subroutine For Voigt Function Evaluation OnVector Processors, Comp. Phys. Commun., 75 135-142.

Ramanathan, V., L. Callis, R. Cess, J. Hansen, I. Isaksen, W. Kuhn, A. Lacis, F. Luther, J. Maldman, R. Reck, and M. Schlesinger, 1987: Climate-chemical interactions and effects of changing atmospheric trace gases, Reviews of Geophysics, 25 (7), 1441-1482.

Ramaswamy, V., 1993: Private Communication.

Rothman, L.S., R.R. Gamache, R.H. Tipping, C.P. Rinsland, M.A.H. Smith, D.C. Benner, V. Malathy Devi, J.M. Flaud, C. Camy-Peyret, A. Perrin, A. Goldman, S.T. Massie, L.R. Brown, and R.A. Toth, 1992: The HITRAN Molecular Database — Editions of 1991 and 1992, Journal of Quantitative Spectroscopy \& Radiative Transfer, 48, 469-507.

Shine, K.S., 1993: Private Communication.

Tzen, Ten H. and Lionel M. Ni, 1993: Trapezoid Self-Scheduling: A Practical Scheduling Scheme for Parallel Computers, IEEE Transactions on Parallel and Distributed Systems, 4(1), 87-98. 